\title{
LUTAS SOCIAIS E CIDADANIA: REFLEXÕES SOBRE OS MOVIMENTOS SOCIAIS COMO ELEMENTOS DE RESISTÊNCIA E POSICIONAMENTO POLÍTICO DA SOCIEDADE BRASILEIRA
}

\author{
(1) Herculis Pereira Tolêdo \\ Mestrando Pontifica Universidade Católica, Rio de Janeiro \\ herculisp@hotmail.com
}

\section{RESUMO}

Este trabalho tem como objetivo trazer reflexões acerca do papel que os movimentos sociais constituíram enquanto elementos de resistência e posicionamento político da sociedade. Entende-se que os movimentos sociais constituíram a tática mais adequada na defesa dos direitos da cidadania, pois aprimorou a democracia ao permitir que os indivíduos, as minorias e, mesmo, as maiorias oprimidas, participassem diretamente do processo político. O esforço desta analise concentra-se na contribuição que os movimentos sociais tiveram na história das conquistas sociais no Brasil, sobretudo após a redemocratização. Para isso, recupera-se o processo de construção da cidadania no Brasil, nas ultimas três décadas, destacando o cenário político e a participação da sociedade civil organizada. O texto está organizado em três partes, inicia-se pela discussão sobre os princípios da ação coletiva e de qual maneira esse debate contribui para compreensão dos novos movimentos sociais. Em seguida, faremos uma leitura dos autores que em seus estudos avaliaram a contribuição dos movimentos sociais na trajetória de lutas por direitos e cidadania no Brasil, após o período da redemocratização. Finalmente, será realizada uma analise sobre reconhecimento e redistribuição presentes nas reflexões dos movimentos reivindicatórios contemporâneos no país.

Palavras chaves: movimentos sociais, cidadania, democracia.

\section{AÇÃO COLETIVA: O ARCABOUÇO TEÓRICO DOS NOVOS MOVIMENTOS SOCIAIS}

O pesquisador italiano Alberto Melucci dedicou a sua vida profissional a entender os movimentos sociais contemporâneos. Para ele,

“(...) o movimento social não é uma resposta a uma crise, mas sim a expressão do conflito que é levado para além do sistema de relações sociais a que a ação se destina (rompe as regras do jogo, propõe objetivos não negociáveis, coloca em questão a legitimidade do poder, e assim, por diante."(Melucci, 2001, p. 35)

Melucci entende que as pessoas não são simplesmente moldadas por condições estruturais; elas se adaptam e dão sentido próprio às condições que determinam suas vidas, criando formas próprias de interação dentro das condições estruturais nas quais estão integradas.

Segundo Melucci (2001), o processo de construção de um sistema de ação em que o ator elabora e avalia possibilidades e limites de sua ação, exige, portanto, a capacidade do ator de se definir a si mesmo e o ambiente em que está inserido. 


\section{SEMINÁRIO DE PESQUISA EM CIÊNCIAS HUMANAS - SEPECH \\ Humanidades, Estado e desafios didático-científicos \\ Londrina, 27 a 29 de julho de 2016}

A informação é uma das condições fundamentais para a sobrevivência e o desenvolvimento da sociedade. Na perspectiva melucciana, os movimentos sociais exigem sujeitos com capacidade de processar, produzir e difundir informação. Portanto, é vital esta capacidade aos atores que desejam interferir na lógica de funcionamento da sociedade.

Desse modo, Melucci enfatiza a importância tanto dos canais de comunicação internos na construção das redes que formam os grupos sociais, quanto dos canais externos para a eficácia da tradução das novas demandas para a esfera pública.

De acordo com Melucci, as sociedades complexas se caracterizam pela presença de três elementos fundamentais. O primeiro deles é a diferenciação que se expressa através dos códigos e símbolos existentes nas diferentes esferas da vida cotidiana. O segundo é a variabilidade dos sistemas que está relacionada à velocidade e a frequência das mudanças. E o último elemento, é o excedente cultural que se refere ao conhecimento e às informações colocadas à disposição dos atores.

Esses processos estabelecem uma permanente condição de incerteza, pois cada vez que passamos de um âmbito a outro, temos que assumir novas regras, linguagens e códigos. Portanto, requer atores autônomos com capacidade para produzir, decifrar e transmitir autonomamente os códigos e símbolos.

Desse modo, Melucci (2001) entende que tais movimentos lutam pelo acesso aos bens materiais ou por reformas políticas e, consequentemente, acabam criando novos códigos e símbolos culturais, sobretudo, porque as ações dos sujeitos alteram a lógica dominante no terreno simbólico, questionam a definição dos códigos, a leitura da realidade e anunciam à sociedade que algo mais é possível.

O autor afirma que "os movimentos sociais são construções sociais (...) são sistemas de ação no sentido de que suas estruturas são construídas por objetivos, crenças, decisões e intercâmbios, todos eles operando em um campo sistêmico". (Melucci, 2001, p.38)

Melucci (2001) entende o movimento social como uma forma de ação coletiva que abraça muitas dimensões: da solidariedade, do conflito e de ruptura com os limites do sistema em que ocorre a ação. Para o autor, é exatamente a presença destas três dimensões que permite que uma ação coletiva (definida como movimento social) seja separada de outros fenômenos coletivos. A falta de uma dessas dimensões à ação coletiva não pode ser entendida como movimento social. Desse modo, é possível afirmar que há muitas ações coletivas que não são propriamente movimentos sociais.

Nas últimas décadas, é possível constatar um número significativo de estudos acadêmicos que buscou entender quando uma ação coletiva expressa um movimento social. Desde a década de 1960, Touraine deu centralidade ao tema dos movimentos sociais, e como observa Gohn (2014) "sua produção continua vigorosa". A perspectiva touraineana estrutura-se a partir do que se convencionou denominar de paradigma acionalista, isto é, toda ação é uma resposta a um estimulo social, enfatizando a conduta dos indivíduos e grupos em termos de conflito ou de integração.

Desse modo, o movimento social apresenta-se como ação de um grupo, de um ator coletivo. Para Touraine (1984), o ator é aquele que tem consciência da sua subjetividade. Certamente, é nessa defesa que Touraine e Melucci aproximam suas discussões.

Em seus estudos, Touraine (2009) destaca a importância da idéia do sujeito na modernidade. Pois é nela que o sujeito se torna portador de direitos universais. Touraine propõe que o sentido não está mais na situação, dentro do sistema, das instituições, mas na consciência do ator. Nesse sentido "O sujeito é o encontro direto, sem 


\section{SEMINÁRIO DE PESQUISA EM CIÊNCIAS HUMANAS - SEPECH \\ Humanidades, Estado e desafios didático-científicos \\ Londrina, 27 a 29 de julho de 2016}

intermediários, do ser empírico com a imagem dele mesmo como valor para ele mesmo, sem intermediário nem religiosa, nem social" (Touraine, 2009, p.121).

Em "O retorno do ator" (1984) é conferido aos atores sociais papéis de agentes dinâmicos, produtores de reivindicações e demandas. Como observa Gohn, a teoria dos movimentos sociais touraineana é construída ao redor das ações coletivas, das lutas, dos atores, dos conflitos. Mas como nem todas as ações coletivas podem ser definidas como movimentos sociais, o mesmo se aplica a ideia de conflito.

Segundo Touraine (2009), existem muitos conflitos sem movimentos sociais, e muitos movimentos sociais que, mesmo comportando uma dimensão de conflito, atribuem um papel mais forte à afirmação das questões culturais do que ao conflito propriamente dito. Dessa maneira, os conflitos mais importantes não são mais sociais: eles se deslocam em direção a vida pessoal, levando à compreensão que, na perspectiva touraineana, a idéia de sujeito torna-se cada vez mais o fundamento das novas lutas.

Em suma, pode-se concluir que a ação coletiva não é uma categoria que se possa situar à margem da história e da política. As formas contenciosas da ação coletiva associada aos movimentos sociais são históricas e socialmente distintas, podendo desafiar opositores, despertar solidariedade e significados para os atores sociais. Certamente, essa discussão qualifica o tipo de ação coletiva que tem sido caracterizado como movimento social.

\section{DÉCADA DE 90: CONTRIBUIÇÃO DOS MOVIMENTOS SOCIAIS NA TRAJETÓRIA DE LUTAS POR DIREITOS E PELA CONSTRUÇÃO DA CIDADANIA NO BRASIL}

A década de 90 é um marco para democracia e para a política social brasileira. É nesse período que os movimentos sociais e organizações se lançam na luta pela redemocratização da sociedade e do Estado e é a partir da Constituição de 1988, que o cidadão passa a ter o direito de, perante a administração pública, opinar sobre as prioridades, participar, decidir, compartilhar, validar e proteger a aplicação dos recursos públicos na geração de benefícios à sociedade.

Paiva (2014) observa que a redemocratização significou uma nova articulação entre sociedade civil e esfera pública no país. Foi preciso esperar quase duas décadas para que novas formas de associação pudessem ser repensadas como no caso do sindicalismo com as organizações que pautaram a agenda pública, ligada à maior justiça social ou como os movimentos sociais que se organizaram para luta reivindicatória dos mais variados tipos de direitos sociais.

O processo de construção da cidadania no Brasil nunca foi linear. No entanto, é nos anos 1980 que se inauguraram novos tempos para a cidadania. É nesse período que vários militantes de lutas sociais no país aliaram-se a novos parceiros, sem tradição associativa, iniciaram várias frentes de articulação, fundaram organizações, lideraram movimentos, possibilitando uma nova proposta social no país que influenciaria mudanças na cultura política nacional. É o que Dagnino caracteriza por uma nova prática de cidadania, filantrópica e solidária. Isto é, a cidadania passa a ser, portanto, responsabilidade moral e não mais estatal. Semelhantes às ações no mercado, a cidadania também é privatizada, retirada de seu sentido público defendido pela “Constituição Cidadã" de 1988. 


\section{SEMINÁRIO DE PESQUISA EM CIÊNCIAS HUMANAS - SEPECH \\ Humanidades, Estado e desafios didático-científicos \\ Londrina, 27 a 29 de julho de 2016}

A solução encontrada foi a criação de espaços públicos dentro do Estado, nos quais é legitimada a participação do cidadão na gestão pública, na fiscalização, no monitoramento e no controle das ações da administração e acompanhamento das políticas públicas, portanto, um importante mecanismo de fortalecimento da cidadania.

As ações coletivas nos anos 1980, no Brasil, foram impulsionadas pelos anseios de redemocratização, pela crença do poder da participação popular, em especial, movimentos sociais que expressaram a construção de um novo paradigma de ação social, fundado no desejo de se ter uma sociedade diferente, sem descriminações, exclusões e segmentações. Os anos 1990, talvez venham a ser denominados no Brasil como a década das lutas cívicas pela cidadania. É neste período que ocorre a ascensão de lutas que afetaram grandes conjuntos da população, refletindo no cotidiano da vida dos cidadãos.

Segundo Dagnino (1994), é a partir dos anos 90 que surge uma nova noção de cidadania, a qual está intrinsecamente ligada à experiência concreta dos movimentos sociais, tanto os do tipo urbano quanto os movimentos de mulheres, negros e homossexuais. Para ela, a organização desses movimentos aliada à luta por direitos tanto de igualdade como da diferença - constituiu a base de uma nova noção de cidadania e, sobretudo, a construção e difusão de uma cultura democrática contributiva à criação de um espaço público onde os interesses comuns e os particulares, as especificidades e diferenças podem ser discutidas. ${ }^{1}$

A autora observa que a nova cidadania requer a constituição de sujeitos sociais ativos, definindo o que eles consideram serem os seus direitos e lutando pelo seu reconhecimento.

Outra característica, segundo Dagnino, é que a nova cidadania constitui uma estratégia dos não cidadãos, dos excluídos - uma cidadania de baixo para cima. Não se vincula a uma estratégia das classes dominantes e do Estado para a incorporação política progressiva dos setores excluídos, com vista à maior integração social ou como condição jurídica e política indispensável à instalação do capitalismo.

A nova cidadania transcende o foco privilegiado da relação com o Estado, ou entre o Estado e o indivíduo, para incluir fortemente a relação com a sociedade civil. O que está de fato em jogo é o direito de participar efetivamente da própria definição desse sistema, o direito de definir aquilo no qual "queremos" ser incluídos. Incorpora tanto a noção de igualdade como da diferença. A afirmação da diferença está sempre ligada à reivindicação de que ela possa simplesmente existir como tal, o direito de que ela possa ser vivida sem que isso signifique, sem que tenha como consequência, o tratamento desigual, a descriminação.

Em síntese, a nova cidadania constituiu um quadro de referência complexo e aberto para dar conta da diversidade de questões emergentes nas sociedades latino-americanas: da igualdade à diferença, da saúde aos meios de comunicação de massa, do racismo ao

\footnotetext{
${ }^{1}$ Um exemplo foi o que ocorreu tanto no âmbito dos Conselhos Populares dos bairros, como na discussão mais ampla no Fórum do Orçamento Participativo de Porto Alegre.
} 


\section{SEMINÁRIO DE PESQUISA EM CIÊNCIAS HUMANAS - SEPECH \\ Humanidades, Estado e desafios didático-científicos \\ Londrina, 27 a 29 de julho de 2016}

aborto, do meio ambiente à moradia. Em especial, incorporou tanto a noção de igualdade como da diferença. A afirmação da diferença está sempre ligada à reivindicação de que ela possa simplesmente existir como tal, o direito de que ela possa ser vivida sem que isso signifique, sem que tenha como consequência, o tratamento desigual, a descriminação.

\section{POLÍTICAS DE RECONHECIMENTO E POLÍTICAS DE REDISTRIBUIÇÃO: O DILEMA CONTEMPORÂNEO}

Não restam dúvidas de que a redemocratização significou uma nova articulação entre sociedade civil e esfera pública no país. No entanto, talvez um dos maiores desafios da democracia contemporânea tenha sido, desde então, encontrar políticas capazes de reduzir as desigualdades sociais.

As mudanças no campo das reivindicações em decorrência das atuações dos movimentos sociais nas décadas de 1980 e 1990 tornam-se evidenciadas e o seu debate se ampliou nos últimos anos, especialmente com os estudos de Nancy Fraser, Charles Taylor e Axell Honneth que têm procurado trabalhar, cada um do seu modo, o termo do reconhecimento como sendo central para teoria critica da sociedade contemporânea.

Os dois últimos, Taylor e Honneth retomaram trabalhos de Hegel para ressaltar a importância do reconhecimento na construção da justiça social, seja para abordar os dilemas do multiculturalismo, para refletir sobre as lutas voltadas para a construção da cidadania, para compreender os possíveis efeitos de políticas públicas que se querem inclusivas ou para diagnosticar padrões simbólicos desrespeitosos. Mas todos demonstraram que o conceito de reconhecimento mostra-se um instrumento heurístico bastante promissor.

Acredita-se que isso ocorre em decorrência do fato que o foco central deixou de ser alusivo apenas à esfera econômica e passa a incorporar outros aspectos, como o das desigualdades culturais, sexuais, raciais e físicas. Tanto nos Estados Unidos, Europa quanto na America Latina, as políticas de viés afirmativo tornam-se uma resposta à desigualdade social que exige não só o reconhecimento mas, em especial, sua reparação. Desse modo, esses novos sujeitos sociais, como as mulheres, negros ou deficientes físicos, passam a exigir respostas para suas condições de desigualdade, que precisam, portanto, ser reconhecidas e reparadas.

Certamente, a discussão sobre os pontos convergentes e divergentes do debate entre Taylor, Honneth e Fraser é de relevante importância para o entendimento das questões centrais do tema do reconhecimento social e do capitalismo contemporâneo e é o que se pretende evidenciar nos decorrer deste trabalho. Mas, antes é preciso esclarecer que, no Brasil, há demandas tanto por redistribuição quanto por reconhecimento. Segundo alguns atores, as políticas públicas brasileiras se caracterizam por privilegiar as questões sociais numa perspectiva universalista, a partir de um modelo redistributivo.

A esse respeito, o estudo de Fraser (2001) contribui com essa discussão. Para ela é imaginável existir uma única alternativa política que possa responder as desigualdades sociais. O reconhecimento e a redistribuição são alternativas distintas de pensar políticas públicas.

As políticas de redistribuição estão direcionadas para redução de carências econômicas e, portanto, direcionadas para a redução de carências econômicas, principalmente pela 


\section{SEMINÁRIO DE PESQUISA EM CIÊNCIAS HUMANAS - SEPECH \\ Humanidades, Estado e desafios didático-científicos \\ Londrina, 27 a 29 de julho de 2016}

redistribuição de renda. Já as políticas de reconhecimento estão voltadas para a valorização de identidades desrespeitadas, para a redução das desigualdades sociais, baseadas em aspectos identitários e culturais.

A autora também evidencia que nem todo sujeito ou grupo que sofre com situações de não reconhecimento vive em situação de carência econômica; e nem todo grupo que sofre desvantagem econômica convive com situações de desrespeito cultural. Na verdade, essas políticas são dimensões que estão dialeticamente relacionadas.

Taylor (1995) contribui com esse debate. Para ele, “(...) o devido reconhecimento não é uma mera cortesia que devemos conceber as pessoas. E uma necessidade humana vital". (Taylor, 1995, p. 242) Essa necessidade vital, segundo o autor, está ancorada na identidade que designa e define quem nós somos.

Para entender a conexão entre identidade e reconhecimento, Taylor (1995) destaca o sentido da linguagem, tanto das palavras quanto dos modos de expressão. É por meio da linguagem no sentido mais amplo que os atores se definem. "Definimos nossa identidade sempre em diálogo com as coisas que nossos outros significativos desejam ver em nós - e por vezes em luta contra essas coisas". (Taylor, 1995, p. 246)

A política da diferença defendida por Taylor vai além da mera tolerância à existência das diferenças individuais e grupais, posto que a tolerância, em última instância, apesar de compor o reconhecimento, enfatiza a idéia de concessão da existência da diferença por outro, não tratando de solucionar os problemas provenientes das sociedades multiculturais. Por isso, Taylor apenas aceita a ideia de reconhecimento que prima pelo respeito das diferenças pela via pública.

É justamente por meio desta nova interpretação de igualdade que serão valorizadas as demais particularidades que formam as identidades dos sujeitos e dos grupos passando a ser, inclusive, garantidas pelos Estados e reconhecidas na esfera pública.

Nesse sentido, não discriminar é tratar diferentemente os diferentes na qual suas especificidades sejam justamente a base de um tratamento diferencial em prol da igualdade. "Não só o feminismo contemporâneo, mas também as relações entre raça e as discussões do multiculturalismo são movidos pela premissa que negar o reconhecimento pode ser uma forma de opressão" (Taylor, 1995, p. 243).

A perspectiva taylorista entende o reconhecimento não como uma questão de cortesia, mas uma necessidade humana. Isso porque pessoas e grupos podem sofrer danos reais se a sociedade os representa com imagens restritivas e depreciativas. Para Taylor, os sujeitos são construções dialógicas e é por meio das interações que eles podem realizar a tarefa de serem verdadeiros com suas próprias originalidades - "se eu não sou [verdadeiro comigo mesmo], eu perco o que o ser humano significa para mim".

Honneth é um autor que parece concordar com Taylor quando afirma que é por meio do reconhecimento que os sujeitos podem garantir a plena realização de suas capacidades e uma autorrelação marcada pela integridade. Para Honneth, os sujeitos são forjados em suas interações, sendo que eles só conseguirão sua autorrelação caso se vejam reconhecidos por seus parceiros de interação.

Honneth atualiza a idéia hegeliana por meio da psicologia social de George H. Mead. Assim como Hegel, Honneth defende a gênese social da identidade e vê a evolução moral da sociedade na luta por reconhecimento.

Cabe destacar que Fraser tem uma concepção não culturalista de reconhecimento, que difere marcadamente de Taylor e Honneth, os quais, de modo geral, vêem através da lente da identidade. Segundo Fraser, o não reconhecimento apropriado consiste na depreciação de tal identidade pela cultura dominante e há o consequente dano para o 


\section{SEMINÁRIO DE PESQUISA EM CIÊNCIAS HUMANAS - SEPECH \\ Humanidades, Estado e desafios didático-científicos \\ Londrina, 27 a 29 de julho de 2016}

sentido de self dos membros dos grupos. Desse modo, políticas de reconhecimento significam políticas de identidade.

Para ela, essa interpretação é deficiente em pelo menos dois aspectos. Primeiro tende a reificar identidades de grupos, promovendo com isso "separatismo e comunitarismo repressivos". Em segundo, "o modelo de identidade obscurece os vínculos entre reconhecimento e redistribuição, barrando, assim, os esforços para integrá-los".

Fraser (2001) propõe uma alternativa para concepção do reconhecimento através da questão de status social. $\mathrm{O}$ que requer reconhecimento não é a identidade especifica de grupo, mas o status dos membros individuais dos grupos como parceiros plenos na interação social. Assim, o reconhecimento inapropriado significa subordinação social, no sentido que os indivíduos inapropriadamente reconhecidos são impendidos de participar como iguais na vida social.

Resumidamente, é possível constar que Fraser propõe um paradigma de reconhecimento assentado na acepção de status e assinala a importância da redistribuição de recursos materiais, defendendo que, em diversos casos, desigualdades sociais não estão calcadas em padrões simbólicos de não reconhecimento. Honneth, por sua vez, alega adotar uma visão mais ampla de reconhecimento, que não se restringiria à dimensão cultural da justiça, encampando os aspectos econômicos.

A teoria do reconhecimento pensa os conflitos sociais como buscas interativas pela consideração intersubjetiva de sujeitos e coletividades. Tendo como alicerce a filosofia hegeliana, autores como Taylor, Honneth ressaltam a construção relacional da identidade, frisando que os sujeitos lutam o tempo todo por reconhecimento mútuo. Segundo esses autores, somente dessa maneira eles podem se desenvolver de maneiras saudáveis e autônomas.

Não restam dúvidas de que o Brasil tem uma vasta experiência com práticas políticas redistributivas, voltadas para a questão da igualdade. Mas, quando pensamos em relação às políticas afirmativas, a experiência é ainda relativa. Entretanto, tais políticas vêm apresentando resultados que contribuíram para a redução de desigualdades sociais no país.

\section{CONCLUSÃO}

O final da década de 1960 trouxe especificidades nas formas de manifestações políticas, demandando novas abordagens sobre compreensão das relações sociais, dos conflitos e dos processos políticos da vida social.

Não restam dúvidas que muito ainda deveria ser avaliado sobre o arcabouço teórico para compreensão da lógica dos movimentos sociais que surgem após a redemocratização do país.

Entretanto, fica evidente o quanto os aspectos descritos sobre os movimentos sociais, tanto os que demandam redistribuição quanto os que pedem reconhecimento, influenciaram mudanças socioculturais e políticas no cenário dos países democráticos. No decorrer dessa exposição, buscou-se evidenciar que os movimentos sociais se 


\section{SEMINÁRIO DE PESQUISA EM CIÊNCIAS HUMANAS - SEPECH \\ Humanidades, Estado e desafios didático-científicos \\ Londrina, 27 a 29 de julho de 2016}

tornaram marcos interpretativos de oportunidades políticas. São concebidos como fonte histórica, marco organizacional, apoio de densas redes sociais e símbolos culturais. No caso do Brasil, mobilizou e influenciou tanto a revisão quanto a constituição de uma nova concepção de cidadania que incorporou tanto a noção de igualdade como da diferença, de uma cidadania mais próxima das ideias de civilidade e respeito aos indivíduos como seres humanos. É um processo ativo, não restrito ao voto, mas diretamente relacionado com a participação dos atores sociais na esfera pública e com o exercício dos direitos. Não resta dúvida de que os movimentos sociais se constituíram como elemento fundamental de resistência e posicionamento político no país.

\section{REFERENCIAS BIBLIOGRÁFICA}

DAGNINO, Evelina. Os movimentos sociais e a emergência de uma nova cidadania. In: Dagnino (org.) Anos 90: política e sociedade no Brasil. São Paulo: Editora Brasiliense, 1994.

FRASER, Nancy. Redistribuição ou reconhecimento? Classe e status na sociedade contemporânea. In: Interseções. Ano 4, nº1,2002.

GOHN, Maria Gloria. Novas teorias dos movimentos sociais. São Paulo: Loyola, 2014. Teorias dos Movimentos Sociais. Paradigmas clássicos e contemporâneos. São Paulo: Loyola, 2014.

HONNETH, Axel. Luta por reconhecimento. São Paulo. Ed.34, 2003.

MELUCCI, Alberto. A invenção do presente: Movimentos sociais nas sociedades complexas. Petrópolis: Vozes, 2001.

PAIVA, Ângela Randolpho. Movimentos sociais e teoria crítica: notas sobre a redemocratização brasileira. In: D’Araujo, Maria Celina (org.) Redemocratização e mudança social no Brasil. Rio de Janeiro: Editora FGV, 2014.

TARROW, Sidney. O poder em movimento. Petrópolis. Vozes, 2009.

TAYLOR, Charles. A política do reconhecimento. In: Argumentos Filosóficos. São Paulo: Edições Loyola: 1995.

TOURAINE, Alain. O retorno do actor. Lisboa: Instituto Piaget, 1984. . Pensar outramente. Petrópolis. Ed. Vozes, 2007. 